\title{
SPECIES CROSSES IN ANTIRRHINUM
}

\section{GENETIC ISOLATION OF THE SPECIES MAJUS, GLUTINOSUM AND ORONTIUM}

\author{
BY KENNETH MATHER \\ John Innes Horticultural Institution, Merton
}

Received 17.iv.47

\section{(I) THE SPECIES}

A. majus and A. glutinosum both belong to the section Antirrhinastrum of the genus; yet they differ markedly in both morphology and distribution. A. majus is too well known in cultivation to require description here. Its cultivation is world wide in temperate countries, and even its natural distribution seems to be fairly extensive. Bentham and Hooker assign the species to the Mediterranean region generally. Its distribution in Spain and Portugal has been followed more closely by Baur (1932), who described the species as occupying the whole of the northern and western portion of the peninsular.

The distribution of $A$. glutinosum has been given both by Baur (1932) and in the Botanical Magazine (1893). These authorities agree in regarding the species as confined to a small mountain area, the Sierra Nevada region of south-eastern Spain. A closely similar species is found, similarly distributed, in the Pyrenees.

Although $A$. majus is highly variable in cultivation, it shows a number of general differences from $A$. glutinosum. A full description of the latter will be found in the Botanical Magazine (1893). It has a more prostrate habit than $A$. majus, and its leaves are smaller, rounder and hairier. Flower shape is not widely different between the species, but the flowers of $A$. glutinosum are smaller in size. 'They are also preponderantly ivory in colour, though a little anthocyanin is found in them. The young floral buds have a pale red-buff appearance ; but in the adult flower the red anthocyanin appears only as a number of upright lines on the front or inner part of the upper lobe of the corolla.

The strain of $A$. glutinosum used in these experiments was obtained from the Royal Botanic Gardens, Kew, in 1942. It agrees well with the description and illustration in the Botanical Magazine, except that in this country it does not seem to be perennial as claimed in that description. This claim is qualified, however, by the remark that protection by glass is needed if winter survival is to be assured. The failure of our plants to over-winter may thus not be out of harmony with the description. 
Ten inbred lines of $A$. majus have been used in the experiments. Their flower colours are as follows :-

I line--Ivory anthoxanthin with full red anthocyanin.

I line--Ivory anthoxanthin with full shell anthocyanin (pelargonidin derivative).

2 lines-Ivory anthoxanthin with spots and stripes of red anthocyanin, due to an evermutating gene.

2 lines-Ivory anthoxanthin with reduced anthocyanin, appearing as a flush of red colour.

3 lines-Yellow anthoxanthin. No anthocyanin.

I line-Ivory anthoxanthin. No anthocyanin.

The absence or reduction of anthocyanin in seven of the last eight strains depends on the multiple allelomorph series, termed the pal series by Kuckuck and Schick (1930), one member of which is the evermutating gene. The genes causing loss of anthocyanin in one of the yellow strains have not been isolated and classified.

The first nine strains were used for crossing with A. glutinosum. The last was used in a cross with a third species, A. orontium. This is a small-flowered species which grows as a weed in parts of Great Britain. It is said by Bentham and Hooker to have originated in Southern Europe, but now to be widespread as a weed of cultivation over all Europe and Central Asia. It is of upright habit, with narrow leaves and long sepals. In colour, its corolla is magenta-red. This strain of $A$. orontium was also obtained from Kew in $194^{2}$.

\section{(2) NATURAL CROSSES}

It is not clear whether $A$. majus and A. glutinosum have opportunities for intercrossing as wild species. Baur's map suggests that they do not, as their distributions are shown as not overlapping. The possibility of intercrossing when the species are artificially intermingled was, however, tested by an experiment in 1944 .

One hundred plants of $A$. glutinosum and one hundred of $A$. majus were grown in a single outdoor plot of ${ }^{\prime} \mathrm{O}^{\prime} \times 2 \mathrm{O}^{\prime}$, the plants being spaced at $\mathrm{I}^{\prime}$ each way. The hundred plants of majus were further divided into fifty from one of the strains with a mosaic of red on ivory flower colour resulting from the evermutating gene, and fifty from one of the strains with a flush of anthocyanin on ivory flower colour. The two hundred plants were assigned to places at random within the plot. Mortality was somewhat high among the plants of A. glutinosum, and the experiment ended with only seventy-four out of the hundred plants of this species, as compared with all fifty mosaic and forty-nine of the fifty flushed plants of $A$. majus.

Pollination was allowed to take place naturally by insects, chiefly bees, among the plants of the plot. At the end of the season, seed was collected from thirty-three plants of each of the three types. This 
was sown in 1945, and twelve plants were grown from each of the ninety-nine mothers. With a few exceptions these plants survived to flowering, when their origin, whether by intra- or inter-specific pollination could be recorded. The results are set out in table I.

TABLE I

Natural cross-pollination of $\mathrm{A}$. majus and $\mathrm{A}$. glutinosum

\begin{tabular}{|l|c|c|c|c|c|c|c|}
\hline \multirow{2}{*}{ Mother } & \multicolumn{3}{|c|}{ Within species } & Between \\
\cline { 2 - 5 } & $\begin{array}{c}\text { Within } \\
\text { variety }\end{array}$ & $\begin{array}{c}\text { Between } \\
\text { varieties }\end{array}$ & Uncertain & Aberrant & Unclassifiable & Total \\
\hline species & & & & & \\
\hline majus mosaic & 269 & 29 & 22 & 4 & 2 & 67 & 393 \\
majus flushed & 337 & 41 & $\ldots$ & 0 & 1 & 18 & 397 \\
glutinosum & 335 & $\ldots$ & $\ldots$ & $7+3 ?$ & 17 & 38 & 400 \\
\hline
\end{tabular}

Percentages of species crossing

\begin{tabular}{|c|c|c|c|c|}
\hline \multirow{2}{*}{\multicolumn{3}{|c|}{ Mother }} & \multicolumn{2}{|c|}{ Percentage species crosses } \\
\hline & & & Certain & Maximum \\
\hline $\begin{array}{l}\text { majus mosaic } \\
\text { majus flushed } \\
\text { majus pooled } \\
\text { glutinosum }\end{array}$ & . & . & $\begin{array}{l}I \cdot 2 \\
0 \cdot 0 \\
0 \cdot 6 \\
2 \cdot 9\end{array}$ & $\begin{array}{r}18.2 \\
4.5 \\
11.3 \\
12.5\end{array}$ \\
\hline
\end{tabular}

The species hybrids were readily distinguishable by their having flowers with a uniform coloration of somewhat pale anthocyanin on ivory. In $A$. glutinosum intra-specific pollinations would all give the same result ; but in $A$. majus a further classification was possible of the intra-specific pollinations. Crosses between the two varieties, mosaic and flushed, were detectable by their being mosaic on flush.

Certain aberrant types of plant appeared in the progenies. Two of these plants were obviously strays from the families of flushed mothers into a family of a mosaic mother. A third, also in a family from a majus mother, seemed to be a mutant of some kind, and the remaining seventeen were scattered throughout the $A$. glutinosum progenies. These seventeen all showed some signs of having genes from $A$. majus, but they were equally clearly not $\mathrm{F}_{1} s$. It is believed that they represent crosses of the $A$. glutinosum plants with a group of species $F_{1} s, F_{2} s$ and backcrosses which was growing about $400^{\prime}$ away from the natural pollination test plot.

A further apparently aberrant class, including thirty-seven plants, was found in the progenies from A. majus mothers. These had flowers with uniform anthocyanin coloration; yet from the intensity of this 
colour and from their general morphology, they were obviously not species hybrids. They were in fact true A. majus, the product of gametes from the mosaic strain carrying the mutated allelomorph of the ever-sporting gene. Such gametes are known to be produced by the ever-sporting strain. Where the plants appeared in the progeny of flushed mothers, they must have been from the inter-varietal cross within the species. When in the progeny of mosaic mothers their origin is uncertain; they could be from either mosaic or flushed fathers, for the presence or absence of flush could not be detected in them.

A total of I 23 plants out of I I 90 were not in flower at the time of classification and so were unclassifiable. They appear as such in table I. Taking only the plants which were classified and which were not aberrant, the percentages of species crosses in the progenies of the various types of mother are as given in the column marked "Certain" in the lower part of table I. These are all low, the highest being under 3 per cent. It might be objected, however, that the unclassified plants, or a disproportionately high proportion of them, might be species hybrids. Assuming them all to be hybrids, the percentages of species crosses listed in the column marked "Maximum" are found. Even these figures never exceed 20 per cent. ; and it is almost certain that they are gross overestimates.

Species hybrids are generally recognisable in the progenies of A. glutinosum by their foliage. The thirty-eight plants of the progenies which did not flower appeared not to carry an excessive proportion of hybrids as judged in this way. No similar classification is possible in the progenies of $A$. majus mothers. There was, however, no correlation between proportion of hybrids and number classified in these progenies, such as would be expected were the hybrids later flowering and so tending to be left unclassified disproportionately often. In fact, observations on species hybrids over a period of several years suggest that they tend to flower earlier than their A. majus parent.

Thus we have no reason to expect excessive proportions of hybrids in the unclassified plants. The estimates in the "Certain" column are probably reasonably accurate, and species crossing probably did not exceed 3 or 4 per cent. of the pollinations.

Crossing occurs therefore between the species, but it is rare; rarer in fact than varietal crosses within $A$. majus, as shown by the natural crossing of the mosaic and flushed strains ; and rarer too than intraspecific crossing with $A$. glutinosum which, as we shall see, is virtually self-incompatible under outdoor conditions. There must be some means of genetic isolation between the species.

\section{(3) ARTIFICIAL CROSSES}

Genetic isolation of the two species could be brought about in either of two ways. It could be due to a relative failure of the pollen 
of one species to achieve fertilisation after reaching stigmata of the second species, i.e. to interspecific incompatibility such as is known, for example, in Petunia; or it could be due to a relative failure of the pollen of one species to reach stigmata of the other. The former possibility was tested in three ways : by comparison of the success of inter- and intra-specific pollinations as judged by set of capsules; by the segregation of marker genes in the progeny of the species hybrid ; and by the success of inter- and intra-specific pollination in competition after simultaneous double pollination.

The first test was carried out in 1943, using plants both out-ofdoors and in the greenhouse. Self-pollinations, intercrosses of plants of the same species and intercrosses of plants of different species were made and their successes compared. The third species, A. orontium, was included in the outdoor test. The results are given in table 2.

TABLE 2

Pollination tests

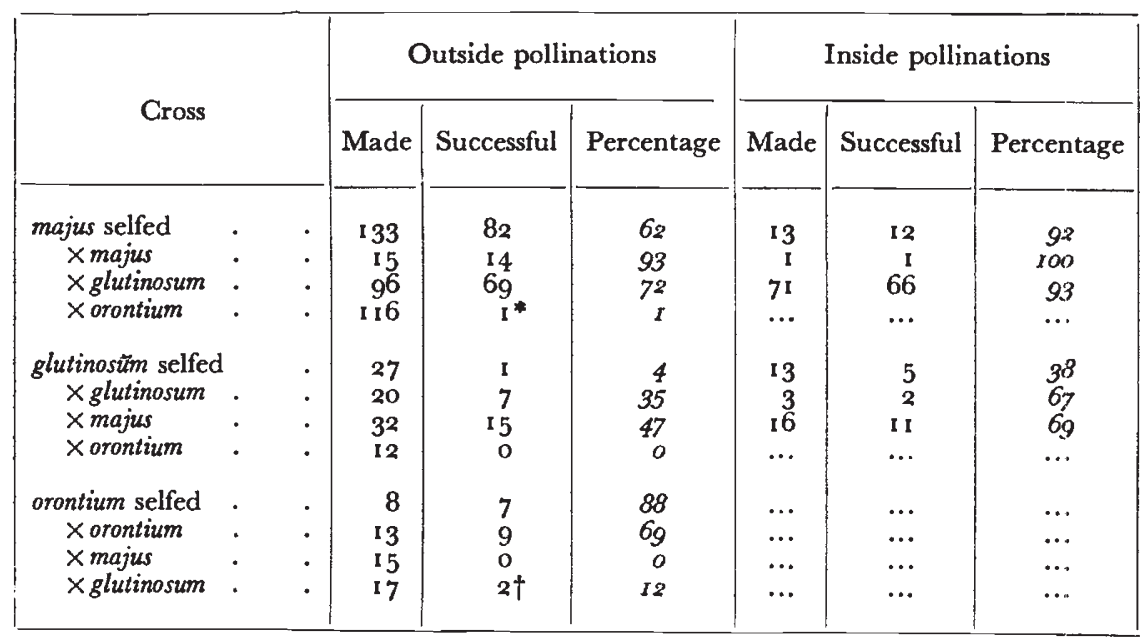

* This seed failed to germinate, but germination had been obtained earlier from a single successful cross.

$\dagger$ This seed failed to germinate.

Outdoor crosses of pairs of A. majus plants were highly successful. Self-pollinations were less so outside, though indoors these selfs were virtually as successful as the outside crosses. The lines used were mainly the inbreds already described. We might expect that, as a result of the effects of inbreeding, self-pollination within such lines would be less often successful than would cross-pollination between them, particularly under outdoor conditions.

The set of capsules on $A$. majus mothers after pollination by A. glutinosum was greater than with self-pollination out-of-doors and much the same as with it in the greenhouse. Inter-specific crossing was somewhat less successful than intra-specific crossing out-of-doors, 
but not significantly so. There was, in fact, nothing to suggest that A. glutinosum pollen was relatively unsuccessful in $A$. majus stigmata.

The pollinations on to $A$. glutinosum mothers tell the same story. In this species, however, self-pollination, even under glass, was relatively unsuccessful, and out-of-doors the species behaves as virtually self-incompatible. Crosses within the species were less often successful than those within $A$. majus, but this may well have been due to the use of inter-incompatible plants as parents in a proportion of cases. Crosses with $A$. majus were actually more often successful than the crosses with other plants of $A$. glutinosum.

In contrast to these results are those obtained when $A$. orontium was used as a parent. This species is easily self-pollinated, and crosses can be made within the species fairly readily. The flower is small and emasculation damage may well account for the small reduction in success of crosses as compared with selfs. A. orontium has, however, never set seed with pollen of $A$. majus and only rarely with that of A. glutinosum. The reciprocal cross has given no capsules with A. glutinosum and only a few with $A$. majus. In only one case, in the year before the test under consideration, has any of the seed from a cross of $A$. majus by $A$. orontium germinated to give hybrid plants. Glearly, although there is no barrier to successful functioning of pollen once pollination has been achieved between $A$. glutinosum and A. majus, there is a strong barrier to the success of pollen in the crosses between these two species on the one hand and $A$. orontium on the other.

For the second test of the success of inter-specific pollination, $\mathrm{F}_{1} \mathrm{~s}$ from crosses of $A$. majus and $A$. glutinosum, made in 1942 , were in I 943 backcrossed both as males and females to the parental species. In these backcrosses segregation can be observed of genes whose differences contribute to the distinction in flower colour of the two species. When such an $F_{1}$ is used as the female parent the segregation reflects only the relative viabilities of the various gametic combinations which are produced by the hybrid. When the $F_{1}$ is used as male, however, pollen competition also affects the segregation observed in the backcross progeny, as the following consideration will show.

Where the parent species differ in a gene or genes causing interspecific incompatibility, pollen from their hybrid will vary, some of it carrying the allelomorph from one species, and some from the other. When this segregating pollen is used on the stigma of either parental species, grains carrying the allelomorph from that same species will grow better, and achieve fertilisation more often, than grains carrying the allelomorph from the other species. Where such incompatibility genes are linked with marker genes affecting flower colour, the segregation of the latter will be correspondingly upset in the male backcross. There will be more of the progeny resembling the species to which the backcross is being made when the $F_{1}$ is used as male than when it is used as female. Such differences in segregation therefore afford a test of the presence of any pollen growth genes by 
which the species may be characteristically distinguished. This test has already revealed isolation genes acting by affecting pollen growth in the species cross between Petunia axillaris and $P$. violacea (Mather and Edwardes, I943).

Crosses of $A$. glutinosum on to the various inbred lines of $A$. majus, on backcrossing to $A$. majus, revealed the action of six different genes. One gene affects the intensity of the anthocyanin pigmentation. A number of allelomorphs from $A$. majus were involved, namely the evermutating gene, another leading to absence of anthocyanin and at least two others giving reduced anthocyanin production (one of which gave the flushed type used in the test of natural pollination). In all cases, $A$. glutinosum contributed an allelomorph giving full anthocyanin pigmentation. The segregations of this series of allelomorphs in backcrosses to $A$. majus are pooled in the first section of table $3(a)$.

The second section of that table shows the joint segregation of two complimentary genes for anthocyanin productions observed in the cross of a yellow anthocyaninless form of $A$. majus by A. glutinosum. One of these genes may be the same as that described above. The third section shows the segregation for a gene affecting anthoxanthin colour, the ivory allelomorph having been introduced from A. majus. The fourth presents data on the segregation for the "delilah" colour patterns introduced by another inbred line of $A$. majus, and the fifth section gives corresponding information about the segregation of a gene causing shell or coral anthocyanin colour in $A$. majus.

The data are pooled in the last section of table $3(a)$, all the individuals carrying the various allelomorphs from $A$. majus being summed above and those carrying allelomorphs from $A$. glutinosum summed below.

In three of the sections the male backcross shows an excess of individuals carrying the allelomorph from $A$. majus as compared with the female backcross; but in the other two the reverse is the case. The pooled data also show a slight excess of $A$. majus allelomorphs in the male backcross. In no case, however, whether of individual segregation or of the pooled data, is the difference between male and female backcross segregation significant when tested by the $\chi^{2}$ appropriate to a contingency table.

Table $3(b)$ gives corresponding data for three segregations in the backcrosses of these same $\mathrm{F}_{1}$ 's to $A$. glutinosum. The segregation for reduced as opposed to full anthocyanin appears to depend on one gene ; but those for absence as opposed to presence of anthocyanin, and for ivory as opposed to pale yellow anthoxanthin, are more complex, probably depending on several genes. The data have nevertheless been pooled, as in the $A$. majus backcrosses, to give a joint test. Again the excess of types having the allelomorph from $A$. glutinosum sometimes shows in the male and sometimes in the female backcross. No significant difference is present in any part of the table. 
In contrast to these results are those of table $3(c)$. The hybrid between $A$. majus and $A$. orontium was backcrossed reciprocally to $A$. majus, the backcross to $A$. orontium failing both ways. Segregation

TABLE 3

Segregation in backcrosses of $\mathrm{A}$. majus $\times \mathrm{A}$. glutinosum to

(a) A. majus

(b) A. glutinosum

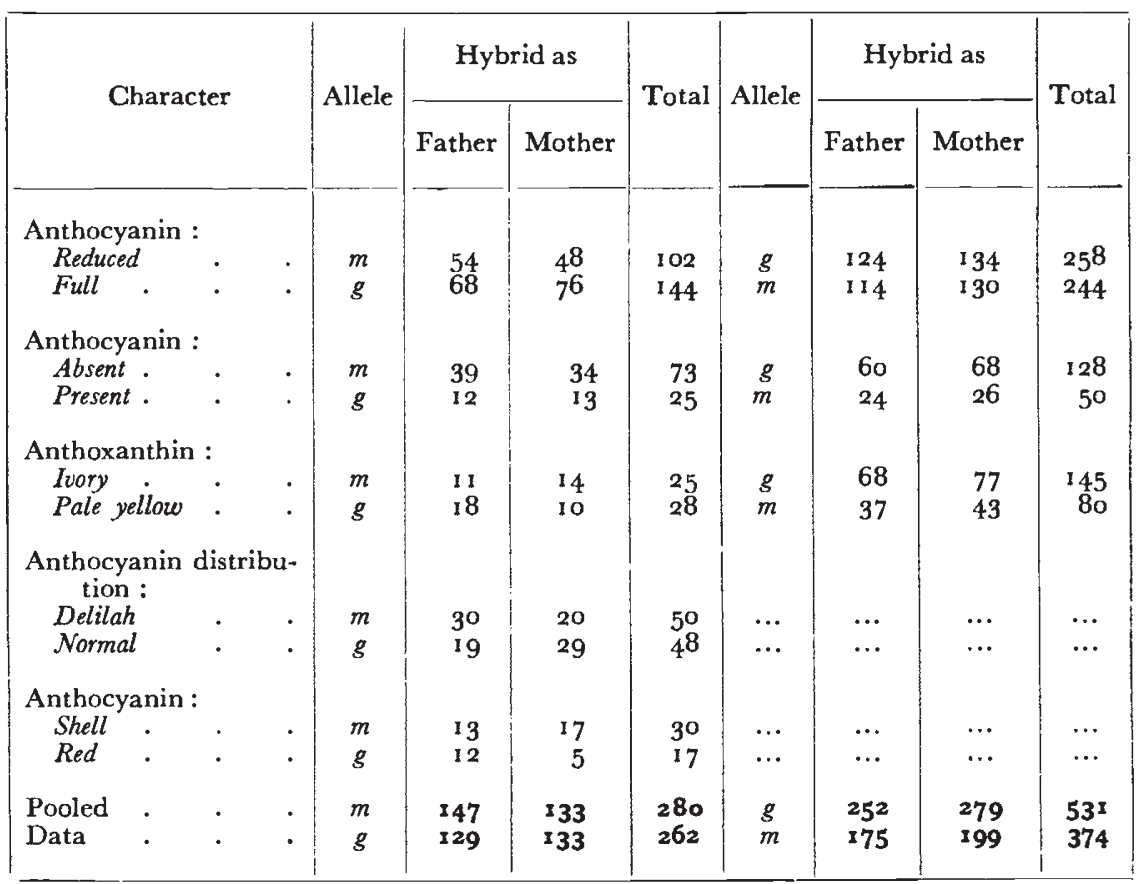

$m$ indicates the class receiving the majus allelomorph(s) and $g$ the glutinosum allelomorph(s) from the hybrid.

(c) Segregation in backcrosses of A. majus $\times$ A. orontium to A. majus

\begin{tabular}{|c|c|c|c|c|}
\hline \multirow{2}{*}{\multicolumn{2}{|c|}{ Allelomorph }} & \multicolumn{2}{|c|}{ Hybrid as } & \multirow{2}{*}{ Total } \\
\hline & & Father & Mother & \\
\hline majus & . & 24 & $4^{8}$ & 72 \\
\hline orontium & . & 10 & 67 & 77 \\
\hline
\end{tabular}

was observed for one gene determining anthocyanin, from $A$. orontium, as opposed to no anthocyanin, from $A$. majus. The female backcross shows an insignificant excess of the allelomorph from $A$. orontium over the expected 0.5 . The male backcross shows an excess, and a significant excess, of the allelomorph from $A$. majus. A contingency 
table $\chi^{2}$ brings out the great significance of the excess of individuals with the $A$. majus allelomorph as the male backcross over the fernale. Selective pollen growth is clearly revealed by these data.

The picture is therefore the same as that shown by the first test. No evidence was found of inter-specific incompatibility genes tending to isolate $A$. majus and $A$. glutinosum by lowering the relative success of pollen on the style of the foreign species ; but there is clear evidence of at least one such gene distinguishing $A$. majus and $A$. orontium.

The third test was confined to $A$. majus and $A$. glutinosum. In 1945 stigmata of flowers of each species were pollinated simultaneously

TABLE 4

Pollination of A. majus and of A. glutinosum with mixtures of pollen of the two species

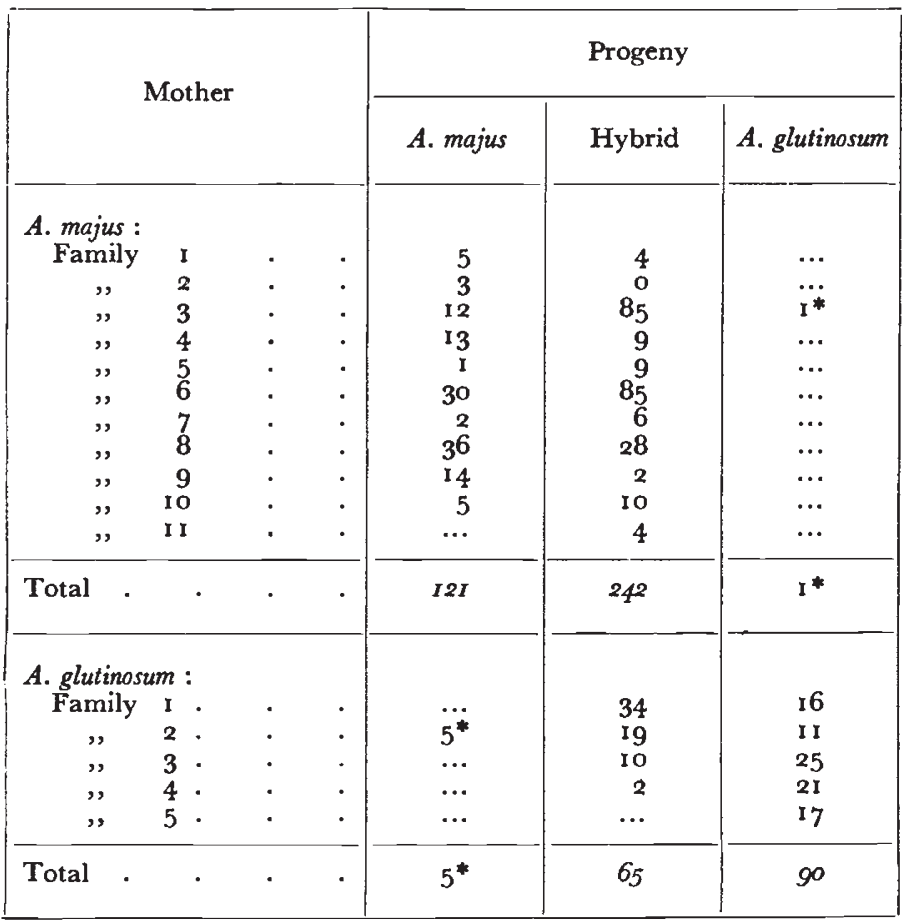

* Presumably these plants are strays.

with pollen of both species. Sometimes this was done by applying first $A$. majus pollen immediately followed by $A$. glutinosum pollen. In other cases the reverse order was adopted. In a third set of pollinations the two types of pollen were mixed as well as possible in a small dish, and the mixture then applied to the stigma. Whenever A. glutinosum stigmata were pollinated, pollen was taken from a different plant of this species for use in conjunction with that from $A$. majus, in order to reduce the risk of complication from the self-incompatibility of 
A. glutinosum. Seed was collected from the capsules to which mixed pollinations gave rise and progenies grown from it in 1945 .

These progenies were classified by means of the flower colour into the two classes obtained from functioning of the two kinds of pollen. As already reported (Mather, I946), the progenies from the A. glutinosum mothers were also earlier classified on the basis of seedling appearance, but this was not possible where $A$. majus was used as mother, because the hybrid closely resembles this species vegetatively. A number of plants died between the two classifications of the progenies from $A$. glutinosum, so that although the results agree in overall appearance they differ a little in numerical detail.

The results from classification on flower-colour are shown in table 4. Both maternal and hybrid plants were obtained from the mixed pollinations on to both A. majus and A. glutinosum mothers. The frequencies are somewhat irregular from family to family, as is to be expected with double pollinations, and there is an overall excess of plants from $A$. glutinosum pollen when used on both types of mother. The excess is, however, smaller with A. glutinosum mothers than with A. majus. It is not to be traced to any isolating mechanism between the species. The small number of aberrant plants in a few of the families cannot detract from the strength of our conclusion. In the experiment as a whole, hybrid plants were as common as those of the two specific types. There is no barrier to the success of the foreign pollen, once the pollination has been made artificially. All three tests agree, therefore, in showing that there is no inter-specific incompatibility between $A$. majus and $A$. glutinosum.

\section{(4) BEE BEHAVIOUR}

Since no isolating mechanism can be found between $A$. majus and $A$. glutinosum once pollination has been achieved, we must look for the isolation in the failure or near-failure of inter-specific pollination under natural conditions. It appears that the pollinating insects, mainly if not entirely bees, do not move pollen from flowers of the one species to those of the other, even though they often transfer pollen from flower to flower and plant to plant within one species.

This conclusion was tested by observations on the bees working over the mixed plot used for the test of natural inter-specific pollination in r 944 . The number of observations of this kind was not so large as could have been desired.* So far as they went, however, the direct observations of bee behaviour confirmed the conclusion reached from the genetical observation of the plants.

Individual bees were seen at work on both species, but no bee was ever seen to enter flowers on a plant of one after entering those on a plant of the other. The bees would move freely from flower to flower and from plant to plant of one species, even flying through an

* Owing to circumstances adversely affecting the conduct of genetical experiments in London during that summer. 
inflorescence of the other kind in so doing; but they never paused to enter flowers of the species with which they were not concerned. $\mathrm{U}_{\mathrm{p}}$ to twenty visits were seen to be made by a single bee without any change in the species visited, the bee then soaring away from the pollination plot, presumably to return to the hive.

Since some species crosses were observed in the progeny of the plants from this plot, it must be assumed that the bees, or other insects, moved from one species to the other in a small proportion of cases. This change-over need not, however, have occurred during one working period: it may have been brought about by a bee returning to the opposite species after a soaring flight of the kind made when visiting the hive. This type of flight has been considered to lead to the rare long distance contamination seen between varieties of the same species (Bateman, I947). The production of the aberrant progeny from $A$. glutinosum by crosses with the derivatives of the species hybrid growing some 400 feet from the pollination plot shows that such long distance contamination was in fact occurring.

These aberrant progeny of $A$. glutinosum were also instructive in another way. It is known that bees can distinguish certain colour differences, including some to which man is not sensitive (Frisch, 1914), and it might be supposed that the flower colour differences between the strains of $A$. majus and $A$. glutinosum, used in the natural pollination plot, were responsible for the distinction which the bees made between them. Some of the aberrant progeny of $A$. glutinosum had, however, coloured flowers, so suggesting that the bees would transfer pollen from plants with coloured flowers to others with white ones. This was confirmed a generation later when nearly one-half of the progeny obtained from a plant of $A$. glutinosum had coloured flowers. It therefore seems that the colour difference cannot be responsible in this case for the differential behaviour of the bees.

Thus bees will not commonly transfer pollen from the one species to the other, even though the plants are growing side by side. They will transfer pollen from $\mathbf{F}_{\mathbf{1}}$ or later derivatives of the species cross to A. glutinosum at least, even though the plants are separated and have unlike flower colours. Flower colour is not the deciding factor. The precise nature of the phenotypic difference between the species which leads the bees to discriminate between them remains to be found out. Further investigation will also be needed to find out how much genetic variation exists within a species, of the kind which would lead to differential bee behaviour, and so would represent the material from which this new type of isolating mechanism could be built up.

\section{(5) SUMMARY}

When grown together in a single plot, and allowed to pollinate naturally, $A$. majus and $A$. glutinosum show less than 3 per cent. inter-crossing. 
Pollination by artificial means is as easy between these species as within them. Furthermore, when stigmata of either species were pollinated simultaneously with pollen from the two, hybrids were produced as commonly as maternal types.

Segregation of marker genes in backcrosses of the inter-specific hybrids reveals no trace of genes determining an inter-specific incompatibility reaction.

There is therefore no mechanism isolating $A$. majus and $A$. glutinosum once pollen has been successfully transferred to a stigma of the opposite type.

The species $A$. majus and $A$. orontium, on the other hand, are isolated by an inter-specific incompatibility reaction, as is shown both by the difficulty of making the hybrid and by the disturbed segregation of a marker gene in the backcross of the hybrid to A. majus.

Observations of bee behaviour show that the mechanism isolating A. majus and A. glutinosum is to be found in the adherence of the bees to one or other species when working over a mixed stand. Pollen transference from one species to the other was never seen to occur.

Bees have been shown to transfer pollen from species hybrids of $\mathrm{F}_{1}$, or a derived generation, having coloured flowers, to $A$. glutinosum with its predominantly white flowers. Some difference other than in flower colour therefore seems to be responsible for the discrimination which the bees make between $A$. majus and $A$. glutinosum.

BAUR, E. $\quad 1932$

\section{REFERENCES}

Artumgrenzung und Artbildung in der Gattung. Antirrhinum, Sektion Antirrhinastrum. Z.I.A.V. $63,256-302$.

BENTHAM, G., and HOOKER, J. D. 1924.

Handbook of the British Flora. 7th ed. Reeve, Ashford.

BATEMAN, A. J. 1947 .

Contamination in Seed Crops. III. Relation between isolation distance and contamination.

Heredity. (In the press.)

Curtis's Botanical Magazine (1 893). Third Series, 49, t 7285.

FRISCH, K. VON. 1914 .

Der Farbensinn und Formensinn der Biene.

Zool. 7 b $b .35,1-183$.

KUCKUCK, H., and SCHICK, R. 1930.

Die Erbfaktoren bei Antirrhinum majus and ihre Bezeichnung.

Z.I.A.V. $56,5^{1-106 .}$

MATHER, K. 1946 .

36th Ann. Report John Innes Hort. Inst. p. 15.

MATHER, K., and EDWARDES, P. J. 1943.

Specific differences in Petunia. III. Flower colour and genetic isolation.

7. Genet. 45, 243-26o. 
Above. Single flowers of $A$. majus (right), A. glutinosum (left upper), A. orontium (left lower), A. majus $\times$ glutinosum (centre upper), A. majus $\times$ orontium (centre lower). About natural size.

Below. Flowering shoots of (left to right) A. orontium, A. majus $\times$ orontium, A. majus, A. majus $\times$ glutinosum, and A. glutinosum. About one-third natural size. 


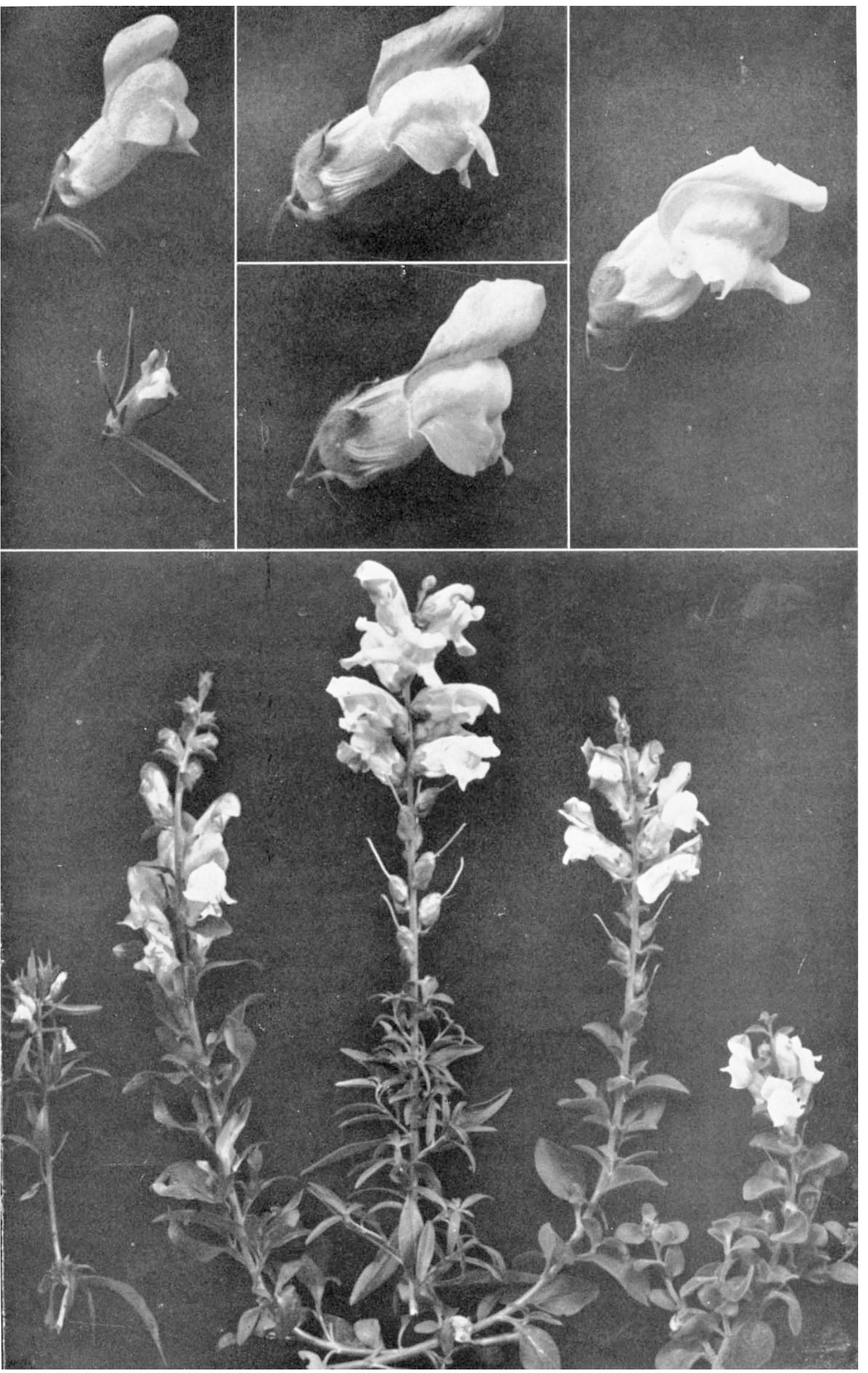

